\title{
El ir y venir de las revistas cientificas de ciencias de la salud en Colombia
}

\section{The back and forth of health-sciences scientific journals in Colombia}

\author{
Oskarly Pérez-Anaya $^{{ }^{\circledR}}$; Jorge-Homero Wilches-Visbal ${ }^{\circledR}$; Midian-Clara Castillo-Pedraza ${ }^{1}$
}

Forma de citar: Pérez-Anaya O, Wilches-Visbal JH, Castillo-Pedraza MC. El ir y venir de las revistas científicas de ciencias de la salud en Colombia. Salud UIS. 53: e21008. doi: https://doi.org/10.18273/saluduis.53.e:21008 @ (c)

Estimado Editor:

Las revistas científicas son reconocidas como el medio de difusión más consolidado de la investigación formal. En gran parte, esto obedece al proceso de revisión exhaustiva de pares y a una minuciosa tarea de selección editorial ${ }^{1}$. En 1996, el Departamento Administrativo de Ciencia, Tecnología e Innovación - Colciencias (hoy Ministerio de Ciencia, Tecnología e Innovación - Minciencias), inició la evaluación oficial de las revistas científicas colombianas, a través de una convocatoria que objetivaba mejorar y formalizar los estándares editoriales de las revistas. Sin embargo, apenas 26 participaron de la convocatoria. Pocos años después, con la expedición del Decreto 1279 de 2002, que regula los salarios y prestaciones de los docentes de las universidades públicas, se le asignó la tarea a Colciencias de elaborar y mantener el Sistema Nacional de Indexación y Homologación de Publicaciones Especializadas de Ciencia, Tecnología e Innovación (Publindex). Desde entonces, Publindex se ha encargado de reconocer e indexar a las revistas colombianas en cuatro categorías: A1, A2, B y C².

Desde su creación hasta el 2014-II, las convocatorias de Publindex se centraron en evaluar criterios como: calidad científica y editorial, estabilidad o regularidad y visibilidad. A medida que avanzaban las convocatorias, se tornaban más estrictos los criterios y con ello el nivel de exigencia. No obstante, esto no fue impedimento para que el número de revistas indexadas incrementaran, tanto así que, en 2014-II, más de 500 revistas del país se clasificaron, de estas entre 10 y $20 \%$ pertenecían a ciencias de la salud.

Con la adopción de un nuevo modelo de indexación/homologación en 2016, basado en indicadores de impacto (H5 de PoP, SJR de Scimago y JCR de WoS), solo se indexaron alrededor de 100 revistas de las 604 que se postularon $^{3}$, generando descontento en la mayoría de los editores de las revistas nacionales, por lo que Publindex lo denominó como un diagnóstico, quitándole toda validez a dichos resultados. Por un lado, este modelo depuró el antiguo modelo, excluyendo revistas de "bolsillo" que se usaban para aprovechar las bondades del 1279. Por otro, fue cuestionado tajantemente porque: i) se centró prácticamente en tales indicadores, ponderando muy a la baja los anteriores criterios; ii) igualó o desmejoró en categoría a revistas indexadas en bases de datos reputadas como Scopus o Web of Science, a pesar de tener H5 igual o superior que otras que no están en tales bases;

1. Universidad del Magdalena. Santa Marta, Colombia.

Correspondencia: Oskarly Pérez Anaya. Vicerrectoría de investigación. Dirección: Carrera 32 No 22-08 Santa Marta D.T.C.H. - Colombia. Teléfono: +57 (5) 4381000. Correo electrónico: oskperez123@gmail.com 
iii) ha promovido la desaparición o el desprestigio de muchas de ellas. En el área de la salud, revistas de gran reconocimiento pasaron de la máxima categoría (A1) a la más baja (C) ${ }^{4}$ (Tabla 1), donde, ahora, permanecer es todo un reto y otras que no han logrado ingresar como la Revista Medicina de la Academia Nacional de Medicina, con más de 100 años de existencia.

Tabla 1. Comparación de las máximas categorías obtenidas por algunas revistas científicas de ciencias de la salud, en el histórico de las convocatorias de Publindex - Minciencias.

\begin{tabular}{lcc}
\hline \multicolumn{1}{c}{ Revistas } & Categoría en modelo anterior & Categoría en modelo vigente \\
\hline Colombia médica & A1 & $\mathrm{B}$ \\
Biomédica & A1 & $\mathrm{B}$ \\
Revista de Salud Pública & $\mathrm{A} 1$ & $\mathrm{C}$ \\
Salud UIS & $\mathrm{A} 2$ & $\mathrm{~B}$ \\
Salud Uninorte & $\mathrm{A} 2$ & $\mathrm{C}$ \\
Vitae & $\mathrm{A} 1$ & $\mathrm{C}$ \\
Universidad y Salud & $\mathrm{A} 2$ & $\mathrm{~B}$ \\
Hacia la Promoción de la Salud & $\mathrm{A} 2$ & $\mathrm{~B}$ \\
\hline
\end{tabular}

A pesar de que el nuevo modelo de Minciencias pueda haber traído mayor rigurosidad y mérito en la indexación, tiene una gran falla: falta de acompañamiento en el proceso de fortalecimiento de las revistas con recursos económicos, ya que de nada vale exigirles a las revistas, sin aportarles algo a cambio, más aún, cuando por no indexarse se reducen, en algunos casos, los apoyos institucionales, creándose una especie de indexar o perecer por no estar en Publindex. Tal vez, las revistas de ciencias de la salud son las que más han sufrido con esta forzosa transición, por lo que se hace un llamado a fortalecerlas y volver a posicionarlas en el lugar de prestigio que en algún momento tuvieron.

Finalmente, queremos llamar la atención de los editores y Publindex para propender por un verdadero Índice Nacional de Medición de Revistas Científicas, que ponderado por factores editoriales y de impacto por igual, refleje más fielmente el inmenso trabajo que se encuentra por detrás de la publicación.

\section{Referencias}

1. Miyahira J. Criterios de calidad de las revistas científicas. Rev Médica Herediana. 2008; 19(1): 1-4.

2. Díaz GM. Incertidumbre ante la implementación del nuevo modelo de medición de revistas científicas en Colombia. TecnoLógicas. 2017; 20(38): 9-13.

3. Colciencias. Informe de la I Etapa de la Convocatoria para la Indexación de Revistas Científicas; 2017. https:// goo.gl/7RNx8j

4. Minciencias. Listado de revistas clasificadas convocatoria 875 de 2020;2020. https://minciencias.gov.co/sites/ default/files/listado_revistas_indexadas_convocatoria_875_de_2020_para_firma_dgc_dic_29.pdf 